\title{
Mesoporous Silica SBA-15 Particles in a Detergent Solution as Abrasive and Coating Material for Household Care Cleaning Products
}

\author{
Athanasios Plomaritis Dimitris Giliopoulos, Konstantinos Triantafyllidis, \\ Margaritis Kostoglou and Thodoris D. Karapantsios * \\ Division of Chemical Technology, School of Chemistry, Aristotle University of Thessaloniki, University Box 116, \\ 54124 Thessaloniki, Greece; plomaritisath@yahoo.gr (A.P.); dimgilio@gmail.com (D.G.); ktrianta@cperi.certh.gr (K.T.); \\ kostoglu@chem.auth.gr (M.K.) \\ * Correspondence: karapant@chem.auth.gr; Tel.: +30-2310-997772
}

Received: 2 December 2018; Accepted: 4 January 2019; Published: 15 January 2019

check for updates

\begin{abstract}
Cleaning products have improved a lot in the last century. The reason for this improvement is not only the use of new surfactants, but also the use of additives that either increase the efficiency of surfactants or act as abrasive agents that increase the mechanical friction during the cleaning process. In this study mesoporous silica (SBA-15) particles are suggested as abrasive additives to a reference detergent as they have a quite soft structure and their shape can act as micro-sponge to collect large amounts of dirt. Indeed, SBA-15 performs very well when added to the detergent, decreasing the effort for primary cleaning of a surface. Furthermore, the properties of the coating layer left behind after primary cleaning with SBA-15 are also examined (i.e., secondary cleaning). It is found that SBA-15 offers no benefit for secondary cleaning. In order to explain this finding, the effect of SBA-15 on the wetting properties of different substrates is studied. It is seen that the SBA-15 coating layer is not uniform. Furthermore, it is seen that dirt is capable of pushing away the coating layer and occupying a large area on the substrate. Contact angle measurements indicate that the substrates become more omniphilic in the presence of SBA-15 coating.
\end{abstract}

Keywords: mesoporous silica; SBA-15; abrasive; wetting; contact angle; coating; wettability

\section{Introduction}

People have always cared about their personal hygiene, and the cleaning of their home and working environment. In the very beginning, cleaning was done by using abrasive materials like sand or small rocks, until soaps were later invented. Over the last two centuries there has been a massive improvement regarding the production of solid soaps, liquid soaps and cleaning powders following the discovery of the detergent action of surfactants. New technologies have come up as result of relevant research studies [1]. Recently, a combination of different materials (e.g., polymers) has been found to increase the efficiency of surfactants and even add some new properties to the final detergent [2]. Another technology that helped the improvement of detergents is the usage of abrasive materials $[3,4]$. Depending on the application, the size of an abrasive material can be of macro, micro or even nanoscale, and its structure can be hard, like diamond or $\mathrm{TiO}_{2}$, or soft like silicone [4].

In a typical house environment, where household care cleaning products are used, there are hard but also sensitive surfaces. For example, the surfaces of glasses and dishes are hard but can be easily scratched and lose their shiny appearance. The same holds for wooden and melamine surfaces which can be hard and at the same time delicate to scratching. In the past, industry produced cleaning products that might damage the surfaces. Nowadays, every candidate cleaning product needs to pass many tests before it reaches the final consumer [4]. 
The main goal of this study is to examine whether there is any benefit in the primary and secondary cleaning properties of a detergent in the presence of mesoporous silica (SBA-15). Particles of SBA-15 are suggested as abrasive cleaning additives because their structure is quite soft, so they cannot harm surfaces, whereas their linear shape increases dirt removal by enhancing mechanical friction during cleaning $[4,5]$. Silica is less hard than materials like diamond or $\mathrm{TiO}_{2}$, and its porous structure makes it even more fragile against the surfaces [6,7]. Moreover, the structure of SBA-15 is like a micro sponge with a large porosity and a huge active surface area, which means that SBA-15 can collect and retain a noticeable amount of dirt. In addition, SBA-15's particles can be easily modified by adding more functional molecules to yield different characteristics. In this respect, two different trimethoxysilanes, (3-glycidyloxypropyl) trimethoxysilane (GPTES), and (3-aminopropyl) trimethoxysilane (APTES), are used herein to modify the SBA-15 surface to increase its cleaning capacity. Colloidal silica dispersions modified by GPTES, which are already used in products, show improved mechanical properties, scratch resistance, water resistance and dirt pick-up resistance in secondary cleaning [8,9]. Coating with APTES either by a free deposition onto the surface or bonding with the surface by hydrolyzing its siloxane shows anti-fingerprint properties, which is oily dirt, and change the wetting properties of the modified surface [10,11].

\section{Materials and Methods}

\subsection{SBA-15 Synthesis and Surface Modification}

The synthesis of mesoporous silica (SBA-15) nanoparticles has been done based on information from the literature [12-14], Figure 1. During a typical synthesis procedure of SBA-15, Pluronic P123 is solubilized in acidic aqueous solution of $\mathrm{HCl} 1.6 \mathrm{M}$ under stirring at $40^{\circ} \mathrm{C}$. When the solution becomes fully transparent, tetraethyl orthosilicate (TEOS) is added very slowly and the solution stays under stirring at $40^{\circ} \mathrm{C}$ for $24 \mathrm{~h}$. The mixture is then transferred into polypropylene (PP) bottles and is aged (no stirring) at $100{ }^{\circ} \mathrm{C}$ for $72 \mathrm{~h}$. The white solid formed is recovered by filtration followed by washing with distilled water, drying in ambient conditions, and calcination in air at $550{ }^{\circ} \mathrm{C}$, for $6 \mathrm{~h}$, with heating rate $1^{\circ} \mathrm{C} / \mathrm{min}$, in order to combust the organic template and produce the mesoporous silica. This synthesis procedure yields a highly porous silica with specific surface (BET) area of $815 \mathrm{~m}^{2} / \mathrm{g}$ and total pore volume of $1.363 \mathrm{~cm}^{3} / \mathrm{g}$ and average pore size (diameter) of $9.7 \mathrm{~nm}$. Moreover, its mechanical stability under external force is relatively low, which has been attributed to an unfavorable wall thickness/unit cell size ratio [7,14]. In Table 1 there is a brief description of the synthesis path [12-16].

Modification of the mesoporous silica surface by epoxy- and amino- units takes place by treatment of SBA-15 with (3-glycidyloxypropyl) trimethoxysilane, GPTES, and (3-aminopropyl) trimethoxysilane, APTES, as seen in Figure 2. Based on the modification method, described in Table 1, the mesoporous silica is initially dispersed in degassed toluene and then the alkyl-trimethoxysilane is added and the mixture stays under stirring at $60^{\circ} \mathrm{C}$ for $24 \mathrm{~h}$. The so-produced modified SBA- 15 is collected by filtration, then is washed in turns by toluene, ethanol, and distilled water, and finally is dried at room temperature. [17-19]. SBA-15 modified herein by GPTES and APTES will be henceforth referred to as SBA-15-1 and SBA-15-2, respectively. The porosity characteristics of these samples are as follows: specific surface (BET) area of $600 \mathrm{~m}^{2} / \mathrm{g}$, total pore volume of $1.251 \mathrm{~cm}^{3} / \mathrm{g}$ and average pore size (diameter) of $8.9 \mathrm{~nm}$ for SBA-15-1, and specific (BET) area of $382 \mathrm{~m}^{2} / \mathrm{g}$, total pore volume of $0.758 \mathrm{~cm}^{3} / \mathrm{g}$ and average pore size (diameter) of $8.5 \mathrm{~nm}$ for SBA-15-2. It is clear that both the porosity and the surface area have been reduced compared to those of the parent SBA-15 silica, indicating the partial coverage of internal surface by the grafted GPTES and APTES moieties and/or the partial blocking of the pores entrance. The successful loading of the organic molecules was proven be elemental analysis measurements which showed the following carbon for the three SBA-15 samples: $\sim 0$ wt. \% for the parent SBA-15 silica, $3.45 \mathrm{wt}$. \% for the SBA-15-1, and $9.54 \mathrm{wt}$ \% for the SBA-15-2. 

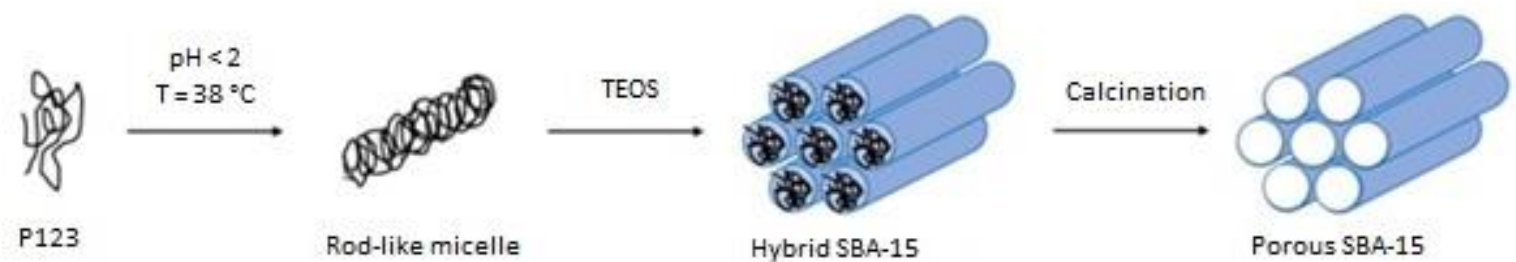

Figure 1. Synthesis of mesoporous silica (SBA-15) [14].
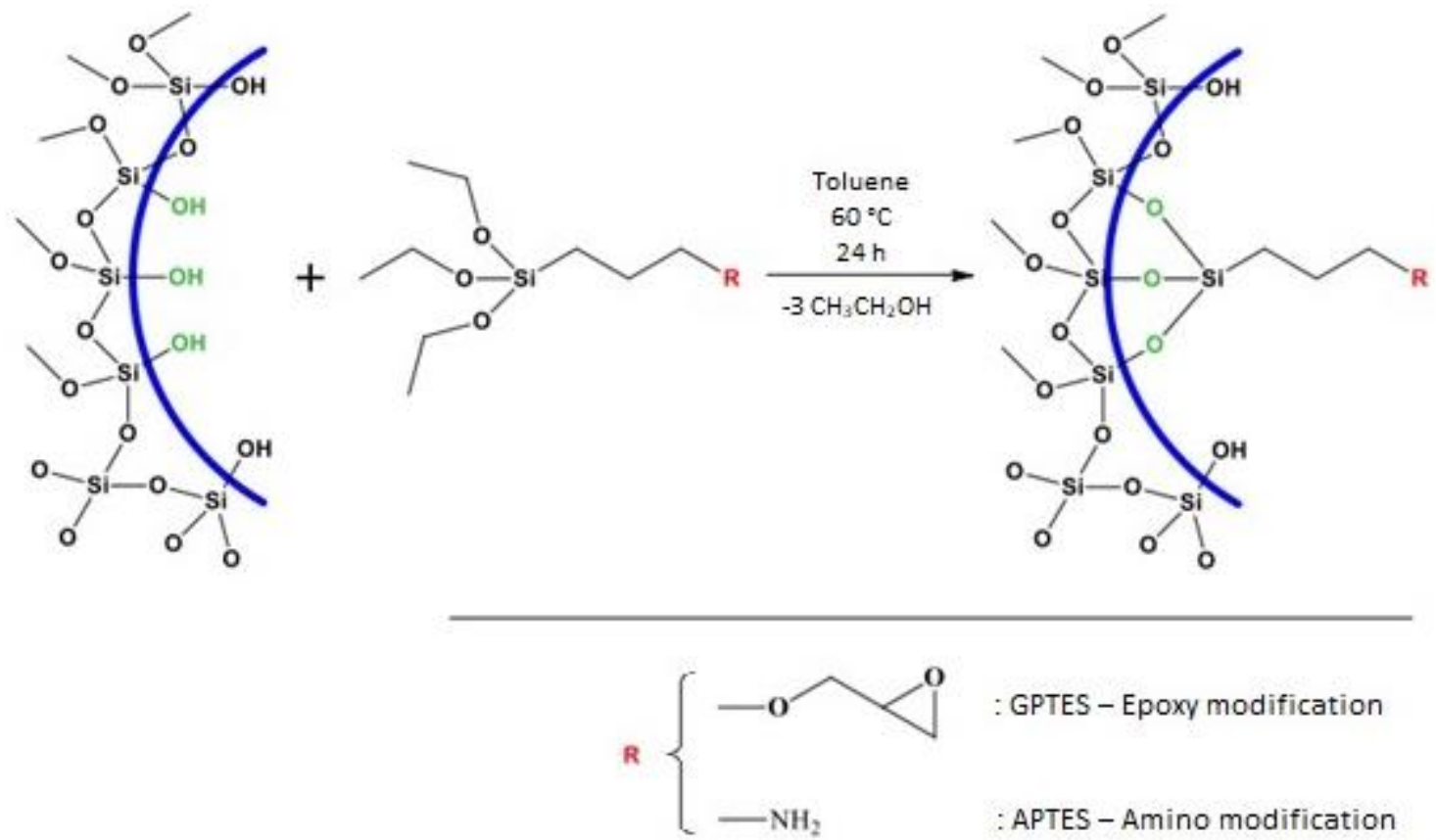

: GPTES - Epoxy modification

: APTES - Amino modification

Figure 2. Mesoporous Silica surface modification by alkyl-silanes [14].

Table 1. Synthesis path of SBA-15 and of modified SBA-15 [14].

\begin{tabular}{|c|c|c|}
\hline Material & Description & Synthesis Path \\
\hline SBA-15 & $\begin{array}{l}\text { SBA- } 15 \text { is a mesoporous silica } \\
\text { with hexagonally ordered } \\
\text { cylindrical pores. }\end{array}$ & $\begin{array}{l}\text { - Pluronic P123 in aq. } \mathrm{HCl}, 1.6\left(40^{\circ} \mathrm{C} \text {, stirring for } 1 \mathrm{~h}\right) \\
\text { - Add TEOS }\left(40^{\circ} \mathrm{C} \text {, stirring for } 24 \mathrm{~h}\right) \\
\text { - Aging of the suspension }\left(100{ }^{\circ} \mathrm{C} \text {, no stirring, } 72 \mathrm{~h}\right) \\
\text { - Filtration, wash by water, dry at room temperature } \\
\text { - Calcination at } 550^{\circ} \mathrm{C} \text { for } 6 \mathrm{~h}, 1^{\circ} \mathrm{C} / \mathrm{min}\end{array}$ \\
\hline SBA-15-1 & $\begin{array}{l}\text { This material is a SBA silica } \\
\text { modified by GPTES, } \\
\text { (3-Glycidyloxypropyl) } \\
\text { trimethoxysilane. }\end{array}$ & $\begin{array}{l}\text { - Dispersion of SBA- } 15 \text { in toluene. } \\
\text { - Addition of GPTES }\left(60^{\circ} \mathrm{C} \text {, stirring for } 24 \mathrm{~h}\right) \\
\text { - Filtration, wash by toluene, ethanol and distilled water } \\
\text { - Drying at room temperature for } 4 \text { days }\end{array}$ \\
\hline SBA-15-2 & $\begin{array}{l}\text { This material is a SBA-15 silica } \\
\text { modified by APTES, } \\
\text { (3-Aminopropyl) } \\
\text { trimethoxysilane. }\end{array}$ & $\begin{array}{l}\text { - Dispersion of SBA- } 15 \text { in toluene. } \\
\text { - Addition of APTES }\left(60^{\circ} \mathrm{C} \text {, stirring for } 24 \mathrm{~h}\right) \\
\text { - Filtration, wash by toluene, ethanol and distilled water } \\
\text { - Dry at room temperature for } 4 \text { days }\end{array}$ \\
\hline
\end{tabular}

\subsection{Detergent Solutions}

An aqueous solution of an ethoxylated alcohol, Neodol $91-5,5 \% v / v$ is used as reference detergent. The selection of this surfactant at this specific concentration is common in the industrial practice of detergency [20]. This detergent solution will be henceforth named as Neo. Three other detergent solutions are prepared in order to examine the effect of SBA- 15 on cleaning performance. These are mixtures of Neodol 91-5, at the prescribed concentration, with SBA15 (henceforth Neo-SBA), with SBA-15-1 (henceforth Neo-SBA1) and with SBA-15-2 (henceforth Neo-SBA2). The concentration of the 
SBA-15, SBA-15-1 and SBA-15-2 in the Neodol 91 solution is $1 \% w / w$. This concentration is usual in tests with this kind of detergents [20].

In this study, only contamination of surfaces by oily dirt is examined because salts and water-dissolvable dirt can be easily removed by a simple stream of water [20].

\subsection{Ergo Ring Testing for Estimation of Primary and Secondary Cleaning Effort}

The experimental work has taken place in Unilever ${ }^{\circledR} R \& D$ Port Sunlight labs. There, the efficiency of cleaning products is tested by an in-house experimental technique named 'Ergo ring". According to this test, a large piece of melamine surface, the size of an A4 sheet $(29.7 \mathrm{~cm} \times 21 \mathrm{~cm})$ is cleaned, dried and sprayed with an oily dirt. The Melamine surface is a hydrophobic epoxy layer. This makes cleaning challenging because dirt and substrate will attach with very strong hydrophobic interactions. After this initial treatment, the dirty substrate is attached to a table equipped with strain gauges which allow measurement of the applied force in three dimensions. The procedure of applying the detergent solution and then trying to clean the dirty surface with it, is described in detail below. The force applied to the substrate to remove the dirt is stepwise increased until the dirt is completely removed. Integration of the applied forces with respect to the duration of their application yields the total cleaning effort. A reference detergent solution is used as the baseline to which the examined SBA-15 solutions are compared regarding the cleaning effort to get the substrate clean. The lower the effort the better the cleaning efficiency of the tested product [20].

A primary cleaning test was made to measure the cleaning efficiency of the suggested solutions where SBA-15 is used as an abrasive additive. Next, the same solutions are tested with respect to possible secondary cleaning benefits. Specifically, it is investigated whether separate application of each SBA-15 solution modifies the substrate, for example by forming a coating layer, and makes it easier to stay clean (repel dirt). The cleaning test is used to estimate the secondary cleaning benefits. For doing this test, a cleaning solution is spread over the surface, then it is rinsed with water for 10 or $30 \mathrm{~s}$ and after that measurements are performed as for the estimation of the primary cleaning efficiency. The statistical significance of the measurements presented below is described by error bars which represent the standard deviation among repetitions.

\subsection{QCM-D Measurements for Estimation of Detergents Coating Efficiency}

Quartz Crystal Microbalance with Dissipation (QCM-D) detects mass deposited onto a quartz crystal surface (that works as a resonator) in real time. This technique is based on the change of the vibrating resonant frequency of the quartz crystal as mass is deposited onto it. QCM-D is very sensitive; it is able to detect mass changes less than $1 \mathrm{ng} / \mathrm{cm}^{2}$, which means that QCM is capable to measure the mass of deposited single layer films of molecules or even atoms [21,22].

The experimental set-up employed for the measurements is an E1 unit, furnished with an open module 401 (both items by Q-Sense). QCM sensors are made of $\mathrm{SiO}_{2}$ - Ti (QSX 335, Q-Sense). QCM chips are cleaned between measurements by rinsing in double distilled water followed by sonication for $30 \mathrm{~min}$ in a bath with Ethanol: $\mathrm{H}_{2} \mathrm{O}$ 50:50. QCM sensors are then rinsed with Decon75 10\% v/v followed by rinsing in double distilled water.

For every measurement, $700 \mu \mathrm{L}$ of double distilled water are added to the QCM cell and the system is allowed to reach a steady frequency. Then the water is replaced by the test solution and is left again to reach steady state at which point the measurement is taken.

\subsection{Contact Angle Measurements for Estimation of Substrates Wetting Properties}

Studies about coatings and films deposited by cleaning products show that the cleaning effort is related to the wetting properties of the substrate and indicate how the coating or the film modifies these properties [23]. Dirt is adsorbed onto a surface because of liquid-solid or solid-solid interactions (Van-Der Waals, London, hydrophobic or arene-perfluoroarene interactions) [24]. The strength of this adsorption is related to the nature of the materials (detergent and substrate), the topography of the 
substrate and the composition of the dirt. On the other hand, for a detergent to be effective it must approach the surface and overcome the interactions between substrate and dirt. Therefore, coatings need to be hydrophilic, since detergents are usually aqueous solutions.

In the present study the wetting properties of surfaces before and after the exposure to SBA-15 solutions are examined. SBA-15 is chosen because it yields better results of primary and secondary cleaning than SBA-15-1 and SBA-15-2. Glass, melamine and Teflon surfaces are employed as substrates. These three materials represent construction materials of surfaces which are commonly used in a house environment.

In order to measure the hydrophilicity/hydrophobicity, oleophilicity/oleophobicity and the surface free energy of the examined surfaces water, dodecane and diiodomethane are used as test liquids. Apart from the static contact angle (CA), advancing and receding CA are also measured using water and dodecane. For the static CA measurements, a droplet of $0.5 \mathrm{~mL}$ is formed at the tip of a needle and the surface is raised to approach the droplet very slowly until the surface touches the droplet. After the deposition of the droplet onto the surface a side-view image is captured. The static CA is calculated from the image using a commercial software. The height of the needle is then adjusted with its tip in the middle of the droplet volume and then a pump is employed to add or withdraw liquid from the droplet. While increasing or decreasing the volume of the droplet a video is taken from which the advancing and receding CA are estimated.

The Owens-Wendt method is used to calculate the surface free energy of the examined surfaces. The static CA values for water and diiodomethane are the inputs for the Owens-Wendt equations in order to compute the dispersive and polar interaction terms of the solid surface. The sum of the dispersive and polar interaction terms equals the surface free energy (SFE) [25-30].

Each surface under examination is cut in a size similar to that of ordinary microscope glass slides. Before doing measurements and before applying any surface coating, a cleaning procedure is followed based on literature suggestions. The substrates are cleaned by a common detergent, rinsed with tap water, rinsed with double stilled water, immersed in two sonicated baths, one filled with EtOH: $\mathrm{H}_{2} \mathrm{O}$ 50:50 for $30 \mathrm{~min}$ and one filled with $\mathrm{MeOH}: \mathrm{HCl} 1 \mathrm{~N}$ for $30 \mathrm{~min}$ and finally dried using filtered air. Treatment with acid is a very drastic oxidation process that can remove persistent contaminants and so erase any previous residual wettability of the examined surface. Yet, there is evidence in literature that treatment of surfaces with very acidic solutions may by itself affect their wetting properties and their surface free energy. To test this, CA measurements and SFE measurements are made before and after the last step of the cleaning procedure with the acidic solution [31-33].

A spin-coater (WS-650-23NPP, Laurell Technologies) is employed to create a film of detergent molecules over the examined substrate. First, the substrate is firmly mounted to the spin-coater plate and a small amount $(\sim 1-1.2 \mathrm{~mL})$ of a detergent solution is spread to cover it entirely. The surface is left covered for $2 \mathrm{~min}$ and then the Spin-Coater is operated for $30 \mathrm{~s}$ at $3000 \mathrm{rpm}$. The values of the above parameters are selected after preliminary tests over a broad range of values to fulfill the requirement of a uniform film over the substrate with a thickness between 200 and 250 nanometers. The coating films that are generated by spin coating are those containing Neodol 91-5. This is because the SBA-15 alone (without the surfactant) is weakly adsorbed on the surface and so during spinning most of it flies away from the surface.

\section{Results}

\subsection{Primary Cleaning}

The efficiency of a detergent solution as cleaning product is measured with the 'ergo ring' test and is expressed as total cleaning effort (Ns). Neodol 91-5 solution (Neo) is used as reference to which the solutions containing SBA-15 (Neo-SBA) and modified SBA-15 (Neo-SBA1 and Neo-SBA2) should compare to. The results of the total cleaning effort are shown in Figure 3. Apparently, the addition of SBA-15 and modified SBA-15 decreases the cleaning effort by more than 50\%. These results may be 
explained by the fact that SBA- 15 offers an appreciable abrasive action that can remove dirt from the substrate. Moreover, if one considers the error bars in measurements there is essentially no difference in the performance of the three SBA-15 detergents.

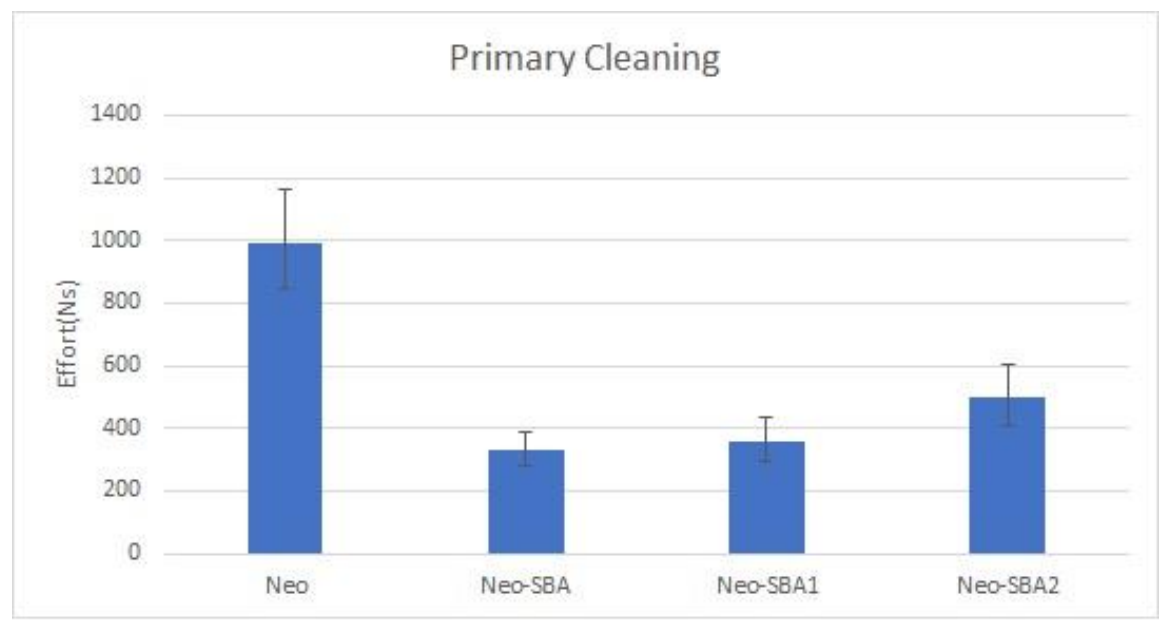

Figure 3. Total cleaning effort based on the ergo-ring test. The first column shows the result for the reference solution without SBA-15.

\subsection{Secondary Cleaning}

Every candidate detergent is tested not only for its primary cleaning performance, but also for its secondary cleaning potential. Ergo-ring measurements, Figure 4, show that there is not any benefit of adding SBA-15 with respect to secondary cleaning. Error bars imply a comparative performance of all the examined detergent solutions regarding the properties of the coating that those solutions leave behind after their application. Since it is not clear why this is so, it is decided to pursuit the issue a bit further.

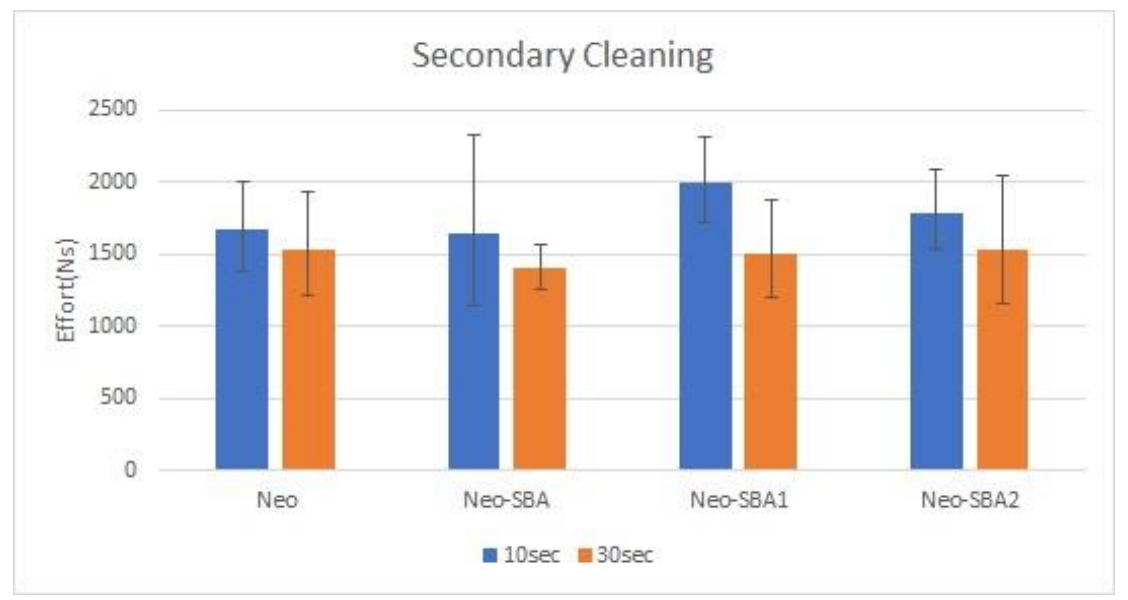

Figure 4. Total cleaning effort for secondary cleaning. The two columns for each detergent solution refer to different rinsing time (10 s and $30 \mathrm{~s}$ ) of the substrate with water before measurements.

\subsection{Coating Efficiency of Neodol $91-5$ and $S B A-15$}

The QCM-D set-up is used to estimate the mass of material adsorbed to the surface of quartz under the exposure scenario employed, leaving a coating after the cleaning procedure, or after the cleaning the amount of the surfactant and the mesoporous silica is completely washed out. Results are presented in Table 2. It is seen that the adsorption of the unmodified SBA-15 is larger than the adsorption of the modified SBA-15-1 and SBA-15-2 and also larger than the adsorption of Neodol 91-5 
alone. Moreover, the combination of Neodol $91-5$ and SBA-15 seems to yield an additive effect and increase the adsorbed mass by an extent fairly comparable to the summation of the surfactant and the SBA-15. In other words, the presence of the surfactant does not facilitate nor magnify the adsorption of SBA-15 and overall, the coated mass of the film on the substrate is not large.

Table 2. Adsorbed mass $(\Delta \mathrm{m})$ of the different materials onto $\mathrm{SiO}_{2}$-Ti surface.

\begin{tabular}{cc}
\hline Material & $\Delta \mathbf{m}\left(\mathbf{n g} / \mathbf{c m}^{\mathbf{2}}\right)$ \\
\hline SBA-15 & 62.59 \\
SBA-15-1 & 24.85 \\
SBA-15-2 & 9.45 \\
Neodol 91-5 & 43.68 \\
Neodol 91-5 with SBA-15 & 91.01 \\
Neodol 91-5 with SBA-15-1 & 74.52 \\
Neodol 91-5 with SBA-15-2 & 52.51 \\
\hline
\end{tabular}

\subsection{Wettability of Substrates}

From the CA measurements (Table 3) and the SFE calculations (Table 4) it is apparent that the treatment of surfaces changes their wetting properties. Treatment with the acidic solution $\left(\mathrm{MeOH}: \mathrm{H}_{2} \mathrm{O}, 1 \mathrm{~N}\right)$, makes the glass more hydrophilic, and the free radicals of Si-O- are covered by hydrogen $[30,31]$. On the contrary, melamine gets more hydrophobic because when contamination is removed the epoxy layer of melamine is exposed and this material is hydrophobic. The wetting properties of Teflon practically don't vary with the treatment. This is because Teflon is very omniphobic.

Application of the solutions of Neodol 91-5 with the SBA-15 particles modifies the wetting properties of the surfaces, making them very hydrophilic but also very oleophilic, as seen in Table 5 . In particular, the glass surface becomes more hydrophilic whereas dodecane is essentially fully spread on the surface (very oleophilic). The same holds also for melamine. Teflon becomes more hydrophilic but its oleophilicity remains practically unchanged. For Neodol 91-5/SBA-15 solution to achieve secondary cleaning benefits, an oleophobic layer should be formed on the surface, which would repel the dirt or at least would keep it poorly attached to the surface. This would have made the surface easier to clean after the first application of the solution (detergent) because an oleophobic film would have covered the surface. However, despite the addition of SBA-15 in Neodol 91-5 improved the primary cleaning of melamine, it did not give any secondary cleaning benefits. This can be explained by the omniphilic character of the SBA- 15 coating. Comparison of Tables 4 and 6 reveals that although the dispersive component of all substrates have increased a bit by the treatment with the Neodol 91-5/SBA-15 solution, the corresponding polar components have increased substantially making the total surface free energy to increase, too. This again manifests the enhanced hydrophilic character of the treated substrates.

In order to investigate further why treatment with the Neodol $91-5$ \& SBA-15 solution doesn't give any secondary cleaning benefits, Scanning Electron Microscope (SEM) microscopy is employed to present morphological features of the modified surface without (Figure 5) and with the dirt on (Figure 6). A Hitachi TM-1000 SEM microscope employed in order to capture these images. The SBA-15 samples used comprise of relatively small primary particles $(\sim 0.5-2 \mu \mathrm{m})$ which have an almost cubic to parallelepiped shape and are edge-aggregated forming larger long particles of 10-100 $\mu \mathrm{m}$, being representative of SBA-15 silica materials. Furthermore, SEM images show that the coating is not uniform, that is, the substrate is not completely covered with the mixture of Neodol 91-5 and SBA-15. The SBA-15 particles build agglomerates on the surfaces. These agglomerates are larger when the surface is sprayed with the solution of the oily dirt. SBA-15 was hoped to stay between the surface and the dirt. On the contrary, the dirt looks like forcing the SBA-15 to form larger agglomerates. The dirt itself stays on the uncovered surface and only a few formations are found to sit on the coating. 
According to the images in Figures 5 and 6, extensive flocculation is observed among the SBA nanoparticles on the substrate. It is not clear if the flocculation occurs first in the bulk solution and then the agglomerates are deposited to the surface or if the flocculation is the result of preferential deposition to positions where there are already SBA particles. In any case, the resulting non-uniformity is due to the higher attractive forces between particles than the forces between particles and substrate. So, the resulting structure of the surface is those of non-uniform islands consisting of SBA agglomerates. Even if the SBA particles are oleophobic, there are still many regions of the substrate surface clean from SBA in a scale such that the apparent contact angle for an oil droplet is not dramatically influenced. On the other hand, the hydrophilic nature of the particles, along with the size of intraparticle voids in the agglomerate, leads to strong capillarity effect that decreases the apparent contact angle of water droplets, despite the large surface portion being free from SBA. Summarizing, the inability to create a uniform (in the sense of minimization of the maximum particle-particle distance) coating layer on the substrate is the reason of the observed poor secondary cleaning performance of the examined cleaning solutions.

The wetting properties of the plain substrate and the coated substrate are key factors determining how strong dirt adsorbs on the surface and how much effort is required to remove it.

Table 3. Contact angle measurements of clean surfaces before the treatment with the acidic solution (Clean) and after the treatment with the acidic solution (MeOH:HCl 1N).

\begin{tabular}{|c|c|c|c|c|c|c|c|c|c|c|c|c|c|c|}
\hline & \multicolumn{6}{|c|}{ Water } & \multicolumn{6}{|c|}{ Dodecane } & \multicolumn{2}{|c|}{ Diiodomethane } \\
\hline & \multicolumn{3}{|c|}{ Clean } & \multicolumn{3}{|c|}{ MeOH:HCl } & \multicolumn{3}{|c|}{ Clean } & \multicolumn{3}{|c|}{ MeOH:HCl } & \multirow{2}{*}{$\begin{array}{c}\text { Clean } \\
s\end{array}$} & \multirow{2}{*}{$\frac{\mathrm{MeOH}: \mathrm{HCl}}{\mathrm{s}}$} \\
\hline & $\mathbf{s}$ & $\mathbf{a}$ & $\mathbf{r}$ & $S$ & $\mathbf{a}$ & $\mathbf{R}$ & $\mathbf{s}$ & $\mathbf{a}$ & $\mathbf{r}$ & $\mathbf{s}$ & A & $\mathbf{r}$ & & \\
\hline Glass & $\begin{array}{c}31^{\circ} \\
( \pm 2)\end{array}$ & $\begin{array}{c}36^{\circ} \\
( \pm 1)\end{array}$ & $\begin{array}{c}9^{\circ} \\
( \pm 2)\end{array}$ & $\begin{array}{c}18^{\circ} \\
( \pm 1)\end{array}$ & $\begin{array}{c}25^{\circ} \\
( \pm 1)\end{array}$ & $\begin{array}{c}8^{\circ} \\
( \pm 4)\end{array}$ & $<3^{\circ}$ & $\begin{array}{c}6^{\circ} \\
( \pm 1)\end{array}$ & n. & $<3^{\circ}$ & $\begin{array}{c}6^{\circ} \\
( \pm 1)\end{array}$ & n. & $\begin{array}{c}48^{\circ} \\
( \pm 4)\end{array}$ & $51^{\circ}( \pm 6)$ \\
\hline Melamine & $\begin{array}{c}50^{\circ} \\
( \pm 2)\end{array}$ & $\begin{array}{c}65^{\circ} \\
( \pm 4)\end{array}$ & $\begin{array}{c}50^{\circ} \\
( \pm 2)\end{array}$ & $\begin{array}{l}96^{\circ} \\
( \pm 2)\end{array}$ & $\begin{array}{l}97^{\circ} \\
( \pm 2)\end{array}$ & $\begin{array}{l}54^{\circ} \\
( \pm 2)\end{array}$ & $<3^{\circ}$ & $\begin{array}{c}6^{\circ} \\
( \pm 1)\end{array}$ & n. & $<3^{\circ}$ & $\begin{array}{c}6^{\circ} \\
( \pm 1)\end{array}$ & n. & $\begin{array}{c}39^{\circ} \\
( \pm 3)\end{array}$ & $38^{\circ}( \pm 2)$ \\
\hline Teflon & $\begin{array}{l}115^{\circ} \\
( \pm 2)\end{array}$ & $\begin{array}{l}123^{\circ} \\
( \pm 1)\end{array}$ & $\begin{array}{l}90^{\circ} \\
( \pm 2)\end{array}$ & $\begin{array}{l}115^{\circ} \\
( \pm 2)\end{array}$ & $\begin{array}{l}127^{\circ} \\
( \pm 2)\end{array}$ & $\begin{array}{l}91^{\circ} \\
( \pm 2)\end{array}$ & $\begin{array}{c}29^{\circ} \\
( \pm 2)\end{array}$ & $\begin{array}{c}36^{\circ} \\
( \pm 1)\end{array}$ & $\begin{array}{c}8^{\circ} \\
( \pm 2)\end{array}$ & $\begin{array}{c}39^{\circ} \\
( \pm 3)\end{array}$ & $\begin{array}{l}36^{\circ} \\
( \pm 1)\end{array}$ & $\begin{array}{c}8^{\circ} \\
( \pm 2)\end{array}$ & $\begin{array}{l}83^{\circ} \\
( \pm 3)\end{array}$ & $75^{\circ}( \pm 6)$ \\
\hline
\end{tabular}

Table 4. Surface Free Energy calculations of clean surfaces before the treatment with the acidic solution (Clean) and after the treatment with the acidic solution (MeOH:HCl 1N).

\begin{tabular}{ccccc}
\hline \multirow{2}{*}{ Substrate } & $\begin{array}{c}\text { Preparation } \\
\text { Method }\end{array}$ & \multicolumn{2}{c}{ SFE Calculation Method: Owens-Wendt } \\
\cline { 3 - 5 } & Clean & $\begin{array}{c}\text { Dispersive } \\
\text { Component }(\mathbf{m N} / \mathbf{m})\end{array}$ & $\begin{array}{c}\text { Polar Component } \\
\mathbf{( m N / m )}\end{array}$ & $\begin{array}{c}\text { Total SFE } \\
(\mathbf{m N} / \mathbf{m})\end{array}$ \\
\hline \multirow{2}{*}{ Glass } & $\mathrm{MeOH}: \mathrm{HCl}$ & $35.38( \pm 2.20)$ & $31.10( \pm 1.69)$ & $66.49( \pm 3.89)$ \\
& Clean & 40.11 & $37.80( \pm 2.36)$ & $71.52( \pm 5.72)$ \\
\hline \multirow{2}{*}{ Melamine } & MeOH:HCl & 40.60 & 17.92 & 58.03 \\
& $\mathrm{Clean}$ & 15.98 & 0.16 & 40.76 \\
\hline \multirow{2}{*}{ Teflon } & $\mathrm{MeOH}: \mathrm{HCl}$ & 20.12 & 0.11 & 16.09 \\
& & & 0.00 & 20.12 \\
\hline
\end{tabular}

Table 5. Contact angle measurements of the substrates after modification with the Neodol 91-5 \& SBA-15 solution.

\begin{tabular}{cccccccc}
\hline \multirow{2}{*}{ Substrate } & \multicolumn{3}{c}{ Water } & & & Dodecane & \multicolumn{2}{c}{ Diiodomethane } \\
\cline { 2 - 7 } & $\mathbf{s}$ & $\mathbf{a}$ & $\mathbf{r}$ & $\mathbf{s}$ & $\mathbf{a}$ & $\mathbf{r}$ & $\mathbf{s}$ \\
\hline Glass & $8^{\circ}( \pm 1)$ & $16^{\circ}( \pm 2)$ & $8^{\circ}( \pm 2)$ & $\mathrm{n}$. & $\mathrm{n}$. & $\mathrm{n}$. & $39^{\circ}( \pm 5)$ \\
Melamine & $6^{\circ}( \pm 2)$ & $12^{\circ}( \pm 3)$ & $10^{\circ}( \pm 3)$ & $\mathrm{n}$. & $\mathrm{n}$. & $\mathrm{n}$. & $31^{\circ}( \pm 6)$ \\
Teflon & $54^{\circ}( \pm 4)$ & $64^{\circ}( \pm 4)$ & $13^{\circ}( \pm 4)$ & $32^{\circ}( \pm 2)$ & $40^{\circ}( \pm 2)$ & $14^{\circ}( \pm 2)$ & $76^{\circ}( \pm 9)$ \\
\hline
\end{tabular}


Table 6. Surface Free Energy calculations of the substrates after modification with the Neodol 91-5 \& SBA-15 solution.

\begin{tabular}{ccccc}
\hline \multirow{2}{*}{ Substrate } & Coating & \multicolumn{2}{c}{ SFE Calculation Method: Owens-Wendt } \\
\cline { 3 - 5 } & & $\begin{array}{c}\text { Dispersive } \\
\text { Component }(\mathbf{m N} / \mathbf{m})\end{array}$ & $\begin{array}{c}\text { Polar Component } \\
(\mathbf{m N} / \mathbf{m})\end{array}$ & $\begin{array}{c}\text { Total SFE } \\
(\mathbf{m N} / \mathbf{m})\end{array}$ \\
\hline Glass & Neodol 91-5 \& SBA-15 & 40.11 & 36.05 & 76.16 \\
Melamine & Neodol 91-5 \& SBA-15 & 43.8 & 34.09 & 77.9 \\
Teflon & Neodol 91-5 \& SBA-15 & 19.59 & 27.03 & 46.62 \\
\hline
\end{tabular}

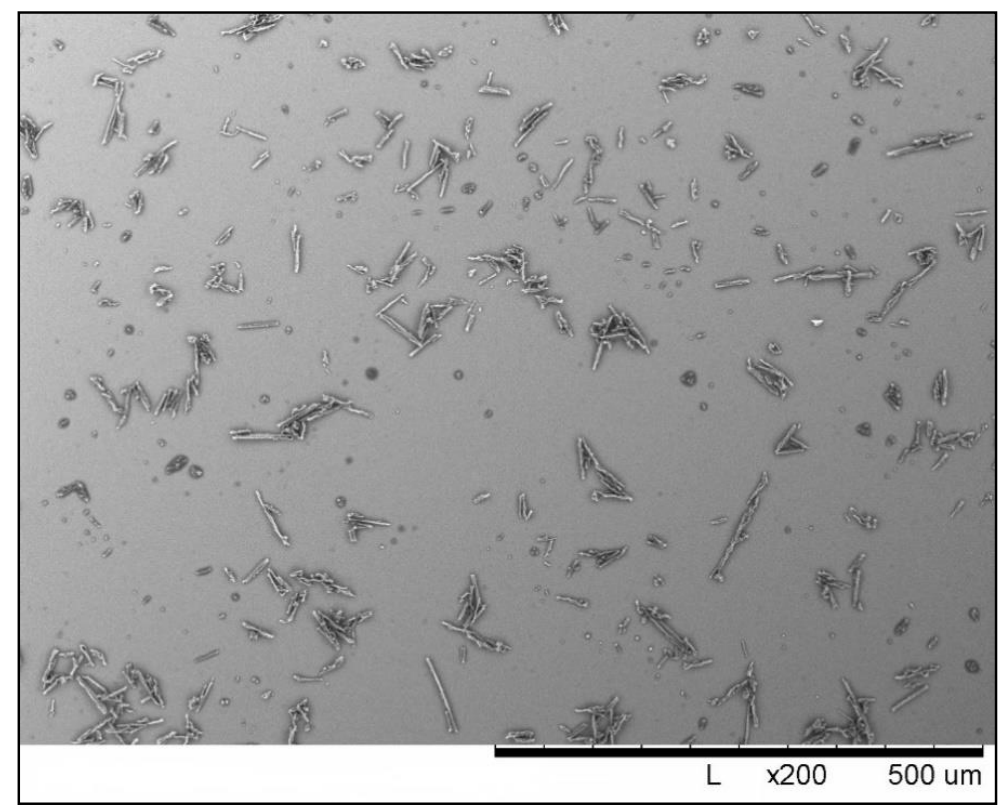

Figure 5. Glass substrate after the modification by the Neodol 91-5 and the SBA-15 solution.

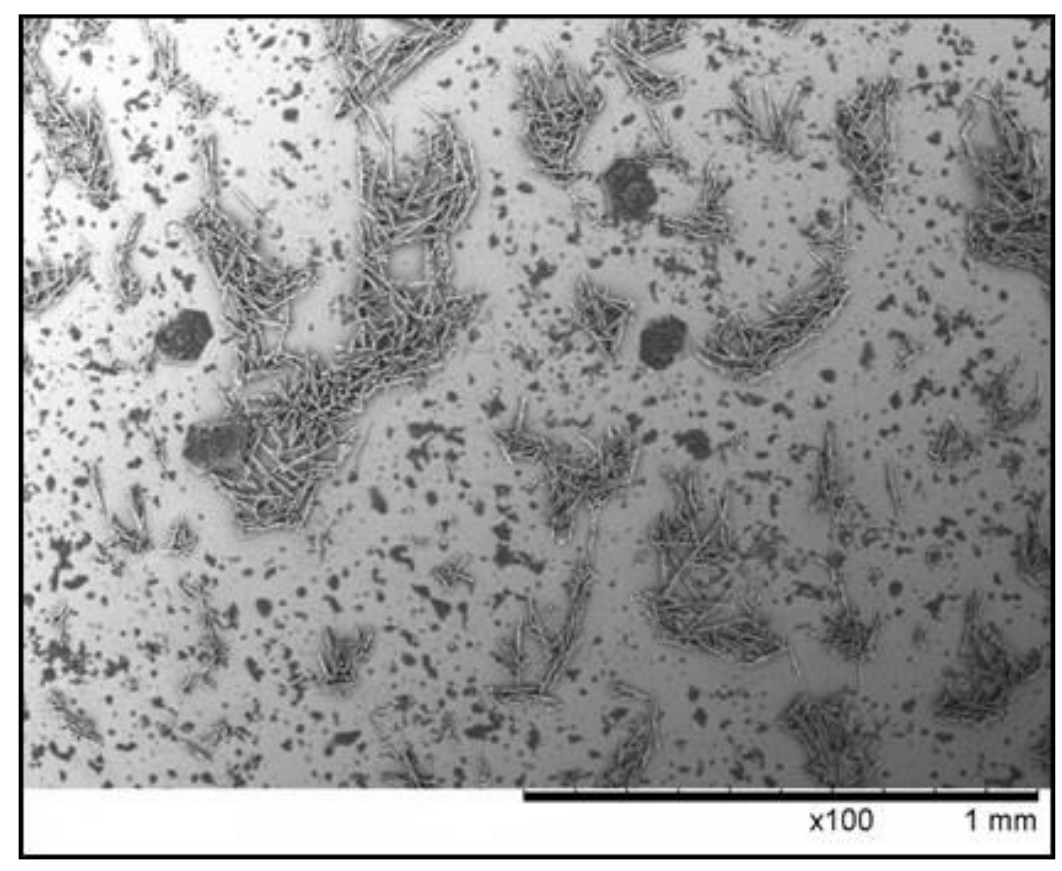

Figure 6. Glass substrate treated with Neodol \& SBA-15 and then sprayed with oily dirt. The dirt stays, black spots, onto the substrate and pushes the coating to form larger agglomerates. 


\section{Conclusions}

The addition of the mesoporous silica SBA-15 in Home Care cleaning products reduce the primary cleaning effort, making the detergent more efficient. The unmodified SBA-15 particles perform better than the modified particles of SBA-15. Unfortunately, the SBA-15 particles left behind on the surface after primary cleaning do not form a uniform film, but instead build agglomerates. This kind of non-uniform coating does not offer secondary cleaning benefits by keeping the surface clean after the first application of the detergent. The oily dirt pushes away particles to form larger agglomerates and occupies a large portion of the surface. Only the larger particles of the dirt sit above the SBA-15 layer. The deposition of mesoporous silica agglomerates changes the wetting properties of the substrates examined in this study. So instead of the desired oleophobic character of the substrates, necessary for achieving secondary cleaning benefits, the glass and the melamine surfaces become much more omniphilic, and even the Teflon surface show enhanced omniphilic properties.

Author Contributions: Conceptualization, A.P. and T.D.K.; methodology, A.P., D.G. and K.T.; validation, A.P. and K.T.; formal analysis, A.P.; investigation, A.P.; resources, K.T. and T.D.K.; data curation, A.P. and M.K.; writing-original draft preparation, A.P.; writing-review and editing, A.P., M.K. and T.D.K.; visualization, A.P., M.K. and T.D.K.; supervision, T.D.K.; project administration, T.D.K.

Funding: This research was funded by Marie-Curie ITN "Complex Wetting Phenomena, CoWet" (FP4-PEOPLE-2013-ITN, grand number 607861).

Acknowledgments: Athanasios Plomaritis kindly thanks Ian Tucker and Giles J. Crowley for the scientific and technical support during his visit in Unilever Research and Development laboratory Port Sunlight.

Conflicts of Interest: The authors declare no conflict of interest.

\section{References}

1. Farn, R.J. Chemistry and Technology of Surfactants; Blackwell Publishing: Oxford, UK, 2006; ISBN 1405126965.

2. Holmberg, K.; Bo, J.; Kronberg, B. Solution and Polymers in Aqueous Solution, 2nd ed.; John Wiley \& Sons: Chichester, UK, 2002; ISBN 0471498831.

3. National Institute for Public Health and the Environment, Ministry of Economic Affairs. Cleaning \& Laundry Products Fact Sheet; National Institute for Public Health and the Environment, Ministry of Health, Welfare and Sport: Bilthoven, The Netherlands, 2018. [CrossRef]

4. Malkin, S.; Guo, C. Handbook of Detergents, 1st ed.; Showell, M.S., Ed.; CRC Press, Taylor \& Francis Group: Boca Raton, FL, USA, 2006; ISBN 9780831132477.

5. Lei, H.; Li, H.; Liu, P.; Chen, R. Preparation and polishing properties of spherical porous silica abrasive. Am. J. Nanotechnol. 2010, 1, 32-39. [CrossRef]

6. Lissel Pilcher Australian Stainless Steel Development Association. Available online: https://www.assda.asn. au/blog/185-coated-abrasives-for-surface-finishing (accessed on 20 June 2018).

7. Canham, L. Mechanical Properties of Porous Silicon. In Handbook of Porous Silicon; Springer International Publishing: Cham, Switzerland, 2014; pp. 1-7.

8. Bindzil CC in Waterborne Coating Applications Product Overviews; AkzoNobel: Amsterdam, The Netherlands, 2011.

9. Colloidal silica dispersions for Hard Surface Cleaning; EKA Chemocals: Bohus, Sweden, 2011.

10. Siriviriyanun, A.; Imae, T. Anti-fingerprint properties of non-fluorinated organosiloxane self-assembled monolayer-coated glass surfaces. Chem. Eng. J. 2014, 246, 254-259. [CrossRef]

11. Zeng, X.; Xu, G.; Gao, Y.; An, Y. Surface wettability of (3-aminopropyl)triethoxysilane self-assembled Monolayers. J. Phys. Chem. B 2011, 115, 450-454. [CrossRef] [PubMed]

12. Meynen, V.; Cool, P.; Vansant, E.F. Microporous and Mesoporous Materials Verified syntheses of mesoporous materials. Microporous Mesoporous Mater. 2009, 125, 170-223. [CrossRef]

13. Burleigh, M.C.; Markowitz, M.A.; Spector, M.S.; Gaber, B.P. Direct Synthesis of Periodic Mesoporous Organosilicas: Functional Incorporation by Co-condensation with Organosilanes. J. Phys. Chem. 2001, 105, 9935-9942. [CrossRef] 
14. Karakoulia, S.A.; Triantafyllidis, K.S.; Lemonidou, A.A. Preparation and characterization of vanadia catalysts supported on non-porous, microporous and mesoporous silicates for oxidative dehydrogenation of propane (ODP). Microporous Mesoporous Mater. 2008, 110, 157-166. [CrossRef]

15. Sanchez, C.; Shea, K.J.; Kitagawa, S. Hybrid materials themed issue organosilicas prepared from bridged organosilane precursors w. Chem. Soc. Rev. 2011, 40, 789-800. [CrossRef]

16. Bao, X.Y.; Zhao, X.S.; Li, X.; Chia, P.A.; Li, J. A Novel Route toward the Synthesis of High-Quality Large-Pore Periodic Mesoporous Organosilicas. J. Phys. Chem. 2004, 108, 4684-4689. [CrossRef]

17. Giliopoulos, D.I. Development of New Nanocomposite Materials of Epoxy Resins with Advanced Nanostructure of Silica. Ph.D. Thesis, Aristotle University of Thessaloniki, Thessaloniki, Greece, November 2015.

18. Stein, B.A.; Melde, B.J.; Schroden, R.C. Hybrid Inorganic-Organic Mesoporous Silicates-Nanoscopic Reactors Coming of Age. Adv. Mater. 2000, 12, 1403-1419. [CrossRef]

19. Rao, A.V.; Kulkarni, M.M.; Amalnerkar, D.P.; Seth, T. Surface chemical modification of silica aerogels using various alkyl-alkoxy/chloro silanes. Appl. Surf. Sci. 2003, 206, 262-270. [CrossRef]

20. Shen, C.; Wang, J.; Tang, Z.; Wang, H.; Lian, H.; Zhang, J.; Cao, C. Physicochemical properties of poly (ethylene oxide)-based composite polymer electrolytes with a silane-modified mesoporous silica SBA-15. Electrochim. Acta 2009, 54, 3490-3494. [CrossRef]

21. Plc, U. Hard-Surface Cleaning Compositions World Intellectual Property Organization. Patent WO1998040452A1, 17 September 1998.

22. Kumar, N.; Garoff, S.; Tilton, R.D. Experimental observations on the scaling of adsorption isotherms for nonionic surfactants at a hydrophobic solid-water interface. Langmuir 2004, 20, 4446-4451. [CrossRef]

23. Kontturi, K.S.; Tammelin, T.; Johansson, L.S.; Stenius, P. Adsorption of cationic starch on cellulose studied by QCM-D. Langmuir 2008, 24, 4743-4749. [CrossRef]

24. Biswal, N.R. Studies on Adsorption and Wetting Phenomena Associated with Solid Surfaces in Aqueous Synthetic and Natural Surfactant Solutions; National Institute of Technology: Odisha, India, 2012.

25. Kwok, D.Y.; Neumann, A.W. Contact angle measurement and contact angle interpretation. Adv. Colloid Interface Sci. 1999, 81, 167-249. [CrossRef]

26. Żenkiewicz, M. Methods for the calculation of surface free energy of solids. J. Achiev. Mater. Manuf. Eng. 2007, 24, 137-145.

27. Rudawska, A.; Jacniacka, E. Analysis for determining surface free energy uncertainty by the Owen-Wendt method. Int. J. Adhes. Adhes. 2009, 29, 451-457. [CrossRef]

28. Quéré, D. Wetting and Roughness. Annu. Rev. Mater. Res. 2008, 38, 71-99. [CrossRef]

29. Hirasaki, G.J. Wettability: Fundamentals and Surface Forces. SPE Form. Eval. 1991, 6, 217-226. [CrossRef]

30. Lam, C.N.C. Study of Advancing \& Receding Contact Angles and Contact Angle Hysteresis; University of Toronto: Toronto, ON, Canada, 2001.

31. Han, Y.; Mayer, D.; Offenhäusser, A.; Ingebrandt, S. Surface activation of thin silicon oxides by wet cleaning and silanization. Thin Solid Films 2006, 510, 175-180. [CrossRef]

32. Cras, J.J.; Rowe-Taitt, C.A.; Nivens, D.A.; Ligler, F.S. Comparison of chemical cleaning methods of glass in preparation for silanization. Biosens. Bioelectron. 1999, 14, 683-688. [CrossRef]

33. Lazauskas, A.; Grigaliūnas, V. Float Glass Surface Preparation Methods for Improved Chromium Film Adhesive Bonding. Mater. Sci. 2012, 18, 181-186. [CrossRef]

(C) 2019 by the authors. Licensee MDPI, Basel, Switzerland. This article is an open access article distributed under the terms and conditions of the Creative Commons Attribution (CC BY) license (http://creativecommons.org/licenses/by/4.0/). 